\title{
SERVICE SATISFACTION AND SPORT CONSUMPTION IN THE FITNESS CENTER IN WARSAW
}

\author{
SYLWIA GOCŁOWSKA, ${ }^{1}$ MONIKA PIĄTKOWSKA ${ }^{2}$
}

RECEIVED

ACCEPTED

JEL

CLASSIFICATION

KEYWORDS

ABSTRACT
Józef Piłsudski University of Physical Education in Warsaw

${ }^{1}$ e-mail: sylwia.goclowska@gmail.com

${ }^{2}$ e-mail: monika.piatkowska@awf.edu.pl

16 February 2017

4 May 2017

D10, I10, M30, M31

satisfaction, service, fitness club, sports consumption

The aim of this research is to determine which factors of consumers' sport consumption behaviour have an impact on service satisfaction. The survey was conducted on 76 clients of a selected fitness club in Warsaw. The questionnaire comprised 7 areas of the club's functioning, measured with respect to two dimensions: service satisfaction and the significance of the tested parameters. Statistical analysis was performed in order to investigate the relationship between sports consumption and satisfaction level. Data analysis confirms a correlation in several parameters between consumer consumption and satisfaction (parameters: number of sports activities to choose $r=0.264, p<0.05$; benefits of having a loyalty card $r=0.279, p<0.05$ ) as well as significance (parameters: terms of payment $r=0.246, p<0.05$; club location $r=-0.234, p<0.05$ ). The results are significant from the standpoint of the management of fitness clubs as they provide a better understanding of consumer satisfaction factors.

\section{Introduction \& literature review}

The motivation behind this study was the phenomenon of an increasing number of fitness clubs each year in order to satisfy the growing demand for sports exercises. There is a continuous growth of interest in sport among society, especially city dwellers, who are taking advantage of fitness clubs' offer more and more eagerly. It is estimated that members of these organizations currently include 50 million of Europeans. In Europe, the fitness 
market is worth approximately 27 billion euros, with Poland being considered to be the fastest growing market in Europe. The number of fitness clubs in Poland totals 2,500 companies, providing services to 2.73 million people (The European Health and Fitness Report, 2015). All over the world sports consumption remains at a high level. Bodet (2009) notes that all of the qualities attributed to postmodern consumers can also be found in the area of sports services. Sport has now, by far, become one of the most important elements of a healthy lifestyle, and it is becoming increasingly popular to exercise it in specially created facilities. Given the diversity of contemporary consumers, organizations providing sports services should adapt their activities to the requirements of consumers, focusing on the new needs of the participants (Seippel, 2006). Sports services have contributed to creating consumers who are both more demanding and more selective. The increasing expectations of sports services have made the club managers to assume a customer-focused approach, which in turn has led to the introduction of customer care initiatives (Robinson, 1999). Consequently, an important challenge faced by fitness organization is generating interest in the services that they offer and adjusting said offer to the requirements of the members. In addition, due to substantial market competition, it is also important to retain a member by establishing a relationship with him or her and providing them a satisfactory experience. Different researchers (e.g. Kelly, Turley, 2001; Al-alak, Alnawas, 2010) suggest that revealing customer notions of service experiences has always been vital to the success of service organizations. As far as the management board is concerned, managers should systematically examine current services from the perspective of their customers and redesign their service products, and environment in which those services are delivered, to their target customers. The provision of a quality experience greatly impacts customer satisfaction and facilitates retaining newly-acquired members (Zeithaml et al., 2006). Such approach to the consumer is, according to the marketing theory, a relationship marketing strategy, where one of the main issues is customer satisfaction. Relationship marketing focuses on building long-term relationships with customers through the marketing mix activities characteristic of the services (7P) that establish, develop and maintain relationships between the company and the consumer (Koi-Akrofi et al., 2012). Especially in the industry of services, relationship marketing - being one of the marketing strategies - has proved very popular lately. The aim of relationship marketing is to build a sustainable competitive advantage by providing customers the services of certain values and obtain their loyalty and satisfaction with the services and products (Koi-Akrofi et al, 2012). Relationship marketing is directly linked with a phenomenon called "customer satisfaction", that is "the feeling you have when your needs as a customer are fulfilled and meeting the customer's expectations for key service quality attributes lead to overall satisfaction with service" (Javadein et al., 2008, p. 3). Satisfied customers will be more likely to use a given service again, or will encourage other potential customers to using the service (Patterson, Spreng, 1997). Furthermore, Oliver (1997) suggests that the company's profit (purchase/repurchase behavior by the consumer) depends, inter alia, on satisfaction. Service quality has a direct impact on consumer satisfaction, which, according to Oliver (1997), can be both a cognitive and an affective aspect. Satisfaction, in turn, directly influences consumer loyalty, which is why consumer satisfaction is recognized as a key motor of effective performance of the organization.

Given the increasing dominance of services, both managers and researchers are forced to pay attention to the issues of service quality perceptions and customer satisfaction. They also need to be aware of specific aspects of their services that influence customers in terms of their satisfaction (Javadein et al., 2008). Especially so knowing that consumer satisfaction is particularly sensitive to the strategy of the marketing mix. Each of the instruments of the marketing mix for services consists of many different factors relevant to customers. Every time we observe more and more publications on topics such as service quality, with satisfaction research constituting a clear testimony to 
the increased importance of service marketing and management (Kelly, Turley, 2001; Ko, Pastore, 2005; Petrick, 2004). Therefore, the authors have decided to determine which factors of consumers' sports consumption behavior have an impact on service satisfaction. Apart from that, analyzing the many fields of activities of a fitness club, the researchers are interested in finding out which areas are best evaluated by customers. The work, thus, raises two basic research questions:

1. How did the surveyed customers evaluate the highlighted areas?

2. Is there a relationship between the level of consumption of services among the respondents and the evaluation of these services?

\section{Method}

This work presents the results of a study conducted at the target sample of respondents. The survey was conducted on 100 clients of a selected fitness club in Warsaw in late May and early June of 2016. 76 clients completed and returned the questionnaire. The group characteristics is presented in Table 1.

The study used an original survey questionnaire covering marketing elements of the fitness club operation based on the tool prepared by Alexandris and Palialia. (1999). Authors added new parameters according to the theory of service marketing and its 7 instruments. The instrument has been designed so that the consumer could evaluate their satisfaction with sports and recreational activities as well as their satisfaction with the studied elements arranged in seven areas of the club's functioning, presented in Table 3. Each area was measured on the 7-point Likert scale, in light of two dimensions: service satisfaction and the significance of the tested parameters.

Table 1. Characteristics of the studied population

\begin{tabular}{|c|c|c|}
\hline \multirow{2}{*}{ Factors } & \multicolumn{2}{|c|}{ Entire population examined $(\mathrm{N}=76)$} \\
\hline & $n$ & $\%$ \\
\hline \multicolumn{3}{|l|}{ Gender } \\
\hline women & 45 & 59.2 \\
\hline men & 31 & 40.8 \\
\hline \multicolumn{3}{|l|}{ Age } \\
\hline$\leq 19$ & 1 & 1.3 \\
\hline $20-24$ & 16 & 21.2 \\
\hline $25-29$ & 18 & 23.7 \\
\hline $30-39$ & 17 & 22.4 \\
\hline $40 \llbracket 49$ & 9 & 11.8 \\
\hline $50 \llbracket 59$ & 10 & 13.2 \\
\hline$\geq 60$ & 5 & 6.6 \\
\hline \multicolumn{3}{|l|}{ Education } \\
\hline elementary & 5 & 6.8 \\
\hline secondary & 16 & 21.2 \\
\hline higher & 55 & 72.0 \\
\hline \multicolumn{3}{|c|}{ Household net monthly income per capita } \\
\hline$\leq P L N 800$ & 12 & 16.0 \\
\hline PLN 801-1,500 & 44 & 58.7 \\
\hline PLN 1,501-2,500 & 12 & 16.0 \\
\hline$\geq$ PLN 2,501 & 7 & 9.3 \\
\hline
\end{tabular}

Source: own study. 
Data analysis revealed 43 instances of no response, 277 indications of "not applicable" and 623 indications of "no opinion." All the responses "not applicable" and "no opinion" were treated as missing data. After accounting for the descriptive statistics, an analysis statistics was conducted, consisting in analyzing the relationship between the sports consumption variables and satisfaction and the significance level of the evaluated parameters. The Pearson's correlation coefficient was used to measure the strength of the relationship with the significance level set at $p<0.05$.

\section{Resulls}

Firstly, the study concerned the consumption of services in the group (Table 2). The group comprised mostly loyal customers as nearly two-thirds (64.4\%) of the people who exercise have been associated with this particular club over a year. The majority of them $(80.2 \%)$ are very active people who declare to use the services offered by the club at least once a week. This is also confirmed by the results concerning the time since when these people exercise. More than a half $(59.2 \%)$ declared having been practicing physical activity for more than four years.

Table 2. The level of consumption of services in the population

\begin{tabular}{lcc}
\hline \multirow{2}{*}{ Factors } & \multicolumn{2}{c}{ Entire population examined (N = 76) } \\
\cline { 2 - 3 } & $\mathrm{n}$ & $\%$ \\
\hline Using the club's services (in years) & 27 & 35.5 \\
$<1$ & 26 & 34.2 \\
$1-2$ & 8 & 10.5 \\
$2.01-4$ & 15 & 19.7 \\
$>4$ & & \\
\hline Frequency of using the services & 1 & 1.3 \\
once every six months & 2 & 2.6 \\
once a month & 12 & 15.8 \\
$2-3$ times a month & 25 & 32.9 \\
$1-2$ times a week & 25 & 32.9 \\
$3-4$ times a week & 9 & 11.8 \\
$5-6$ times a week & 2 & 2.6 \\
7 or more times a week & & \\
\hline Practicing physical activity (in years) & 10 & 12.2 \\
$<1$ & 12 & 15.8 \\
$1-2$ & 8 & 10.5 \\
$2.01-4$ & 45 & 59.2 \\
$>4$ & &
\end{tabular}

Source: own study.

Following, the authors were interested in the overall evaluation of the surveyed areas on a scale of satisfaction and significance (Table 3). In the case of the scale of satisfaction and the scale of significance the highest evaluated area was the club's staff ( $\bar{x}=3.92 ; S D=0.74$ and $\bar{x}=4.32 ; S D=0.56$, respectively). The respondents are most satisfied with the physical appearance of instructors and trainers $(\bar{x}=4.03 ; S D=0.85)$, attitude of the staff toward the customer $(\bar{x}=3.97 ; S D=0.93)$ and physical fitness of the instructors and trainers $(\bar{x}=3.97 ; S D=0.93)$. The aspects they find most important are commitment of the instructors during classes $(x=4.56$; $S D=0.6)$, their know-how $(\bar{x}=4.52 ; S D=0.65)$ and the method of teaching $(\bar{x}=4.43 ; S D=0.84)$. 
The lowest evaluated area, meanwhile, was the promotional activities conducted by the club $(\bar{x}=3.38 ; S D=0.57$ for the scale of satisfaction and $\bar{x}=3.66 ; S D=0.64$ for the scale of significance, respectively). The customer are least satisfied with the number of discount offers targeted to the client $(\bar{x}=3.22 ; S D=0.98)$, use of leaflets and posters in the club's promotional campaigns $(\bar{x}=3.28 ; S D=0.86)$ and the frequency of communication of the club with the client $(\bar{x}=3.37 ; S D=0.95)$. As the least important aspects, the respondents indicated the use of leaflets and posters in the club's promotional campaigns $(\bar{x}=3.37$; $S D=0.95)$, adjusting the club's website to mobile devices $(\bar{x}=3.53 ; S D=0.99)$ and the transparency of the website $(\bar{x}=3.65 ; S D=1.01)$.

Table 3. Average evaluation of the areas studied for the scales of satisfaction and significance

\begin{tabular}{lrrrrrc}
\hline \multirow{2}{*}{ Studied areas } & \multicolumn{3}{c}{ Satisfaction } & \multicolumn{3}{c}{ Significance } \\
\cline { 2 - 7 } & $\bar{x}$ & Me & SD & $\bar{x}$ & Me & SD \\
\hline Fitness club's staff & 3.92 & 3.78 & 0.74 & 4.32 & 4.44 & 0.56 \\
Exercise classes and other services offered & 3.58 & 3.6 & 0.59 & 3.77 & 4.0 & 0.78 \\
Price of exercise classes and other services & 3.31 & 3.25 & 0.7 & 4.1 & 4.0 & 0.72 \\
Promotional activity of the club & 3.38 & 3.44 & 0.57 & 3.66 & 4.0 & 0.64 \\
Appearance and equipment of the club & 3.53 & 3.36 & 0.71 & 4.28 & 4.36 & 0.57 \\
Club location & 3.42 & 3.2 & 0.8 & 4.17 & 4.0 & 0.59 \\
Other aspects of the fitness club's operation & 3.81 & 4.0 & 0.88 & 4.12 & 4.17 & 0.74 \\
\hline
\end{tabular}

Source: own study.

Table 4. Strength of the linear relationship between the level of sport consumption and the evaluated parameters (significance level $-p<0.05$ )

\begin{tabular}{|c|c|c|c|}
\hline & \multirow[b]{2}{*}{ Scale } & \\
\hline & & Parameter & r \\
\hline \multirow{10}{*}{$\begin{array}{l}\text { Using the services provided by the } \\
\text { club (in years) }\end{array}$} & \multirow{8}{*}{ Satisfaction } & Know-how of instructors & 0.245 \\
\hline & & Professional experience of instructors and trainers & 0.275 \\
\hline & & Level of individualization during classes & 0.33 \\
\hline & & Promotions and discounts from basic rates & 0.318 \\
\hline & & Special offers for clients & 0.337 \\
\hline & & Number of lockers available in the dressing room & 0.274 \\
\hline & & Access to club from the place of residence or work & 0.37 \\
\hline & & Customer service efficiency & 0.261 \\
\hline & \multirow{2}{*}{ Significance } & Quality of sports and recreational activities & -0.277 \\
\hline & & Marking, indicators and directions to access the club & 0.289 \\
\hline \multirow{5}{*}{ Frequency of using the services } & \multirow{3}{*}{ Satisfaction } & Number of sports activities to choose & 0.264 \\
\hline & & Benefits of having a loyalty card & 0.279 \\
\hline & & Terms of payment & 0.264 \\
\hline & \multirow{2}{*}{ Significance } & Adjusting the website to mobile devices & 0.245 \\
\hline & & Club location & -0.234 \\
\hline \multirow{4}{*}{ Practising physical activity (in years) } & \multirow{3}{*}{ Satisfaction } & Interior design of the club & -0.24 \\
\hline & & Possibility of access by public transportation & 0.258 \\
\hline & & Timelienss of starting and ending classes & 0.261 \\
\hline & Significance & - & - \\
\hline
\end{tabular}

Source: own study. 
The variables for consumption of services (time and frequency of the use of services in the studied club and the period of physical activity) were subject to further analysis. The authors sought relationship between the level of service consumption among the respondents and the evaluation of these services on the scales of satisfaction and significance (Table 4).

One should, however, note the detailed parameters of the analyzed areas. Table 4 shows only those variables that indicated a statically significant relationship with the level of sport consumption. With respect to the remaining parameters, no statistically significant relationship was observed.

Data analysis confirmed the relationship between the level of consumption and the few areas. In the case of the area related to exercise classes and other services offered by the club, a positive relationship with the period of use of these services was observed $(r=0.36 ; p<0.05)$. Therefore, the longer the respondents use the services, the more satisfied they tend to be with the classes. The same area witnessed a negative correlation with the time of physical activity in terms of significance $(r=-0.278 ; p<0.05)$. The longer the respondents practice physical activity, the less important become for them the activities offered the club, but they tend to evaluate the appearance and equipment of the club more negatively $(r=-294, p<0.05)$.

\section{Limitations}

The conducted study is among the first research examining the consumer satisfaction in the industry of fitness services. However, the limitation of this research is that the present study was based on a limited sample. As consumers of only one fitness center were tested, further research is required.

\section{Conclusions}

One of the prevailing themes in market research is consumer satisfaction. This satisfaction is understood to be a crucial construct, both for the managers and researchers interested in the relations established between services and the consumers. The literature also contains evidence that the service quality is strongly related to consumer satisfaction and loyalty (Zeithaml, Bitner, 2003).

This study demonstrated that the aspect of sports consumption plays a significant role in predicting customer satisfaction. The literature contains reports that evaluation of services and products of companies is linked with customer experience, defined as "the internal and subjective response that customers have to any direct or indirect contact with a company" (Meyer, Schwager, 2007, p. 118). Nevertheless, customer experience is considered a psychological concept, a subjective response developed in the customer that can be associated not only with the organization studied in terms of satisfaction, but also with the previous experiences of the clients, branch of the industry or a given service, product. In the case of this study, a relationship was sought with the aspects of sports consumption. The data analysis confirmed the existence of the relationship between the level of consumption and the few areas.

Managers of fitness clubs need to gain awareness and measure the impact of service quality on the satisfaction of their customers and revisit intentions. The feedback obtained from such practice can be used in introducing strategic improvements with respect to service production, and also service provision that will have an impact on the business and in turn increase profitability. The awareness of which of the examined areas were evaluated least favorably will allow the managers to make significant changes to the services offered to the consumer, especially that the fitness market reveals a need for improvement and acceleration of the development of the fitness industry, 
which stems from the knowledge of the market trend characteristics (Pedragosa, Correia, 2009). However as indicated in the limitations the sample of this study was limited, according to that generalizing the results of that research should be done carefully.

\section{Acknowledgments}

This paper was prepared under the statutory framework of Josef Pilsudski University of Physical Education in Warsaw DM. 49 - "The level of satisfacion of participatns in sport and recreation from marketing operation of fitness clubs", financed by the Ministry of Science and Higher Education in Poland.

\section{References}

Al-alak, B.A. \& Alnawas, I. (2010). Evaluating the effect of marketing activities on relationship quality in the banking sector. International Journal of Marketing Studies, 21, 78-91.

Alexandris, K. \& Palialia, E. (1999). Measuring customer satisfaction in ftness centres in Greece: an exploratory study. Managing Leisure, 4, 218-228.

Bodet, G. (2009). Sport Participation and Consumption and Post- Modern Society: From Apollo to Dionysus? Society and Leisure, 32 (2), 223-241. DOI: 10.1080/07053436.2009.10707791.

Javadein, S.R., Khanlari, A. \& Estiri, M. (2008). Customer loyalty in the sport services industry: the role of service quality, customer satisfaction, commitment and trust. International Journal of Human Sciences, 5 (2), 1-19.

Kelly, S.W. \& Turley, L.W. (2001). Consumer perceptions of service quality attributes at sporting events. Journal of Business Research, $54,161-166$.

Ko, Y.J. \& Pastore, D.L. (2005). A hierarchical model of service quality for the recreational sport industry. Sport Marketing Quarterly, $14(2), 84-97$.

Koi-Akrofi, G.Y., Koi-Akrofi, J. \& Welbeck, J.N.O. (2012). Relationship Marketing Tactics and Customer Loyalty-A Case of the Mobile Telecommunication Industry in Ghana. Asian Journal of Business Management, 5 (1), 77-92.

Meyer, C. \& Schwager, A. (2007). Understanding Customer Experience. Harvard Business Review, 85 (2), 116-126.

Oliver, R.L. (1997). Satisfaction: A behavioral perspective on the consumer. Boston, MA: McGraw-Hill.

Patterson, P.G. \& Spreng, R.A. (1997). Modeling the relationship between perceived value, satisfaction and repurchase intentions in a business-to-business, services context: An empirical examination. International Journal of Service Industry Management, $8(5), 414-434$.

Pedragosa, V. \& Correia, A. (2009). Expectations, satisfaction and loyalty in health and fitness clubs. Int. J. Sport Management and Marketing, 5(4), 450-464.

Petrick, J.F. (2004). Experience use history as a segmentation tool to examine golf travelers satisfaction perceived value and repurchase intentions. Journal of Travel Research, 41, 38-45.

Robinson, L. (1999). Following the quality strategy: the reasons for the use of quality management in UK public leisure facilities. Managing Leisure: an International Journal, 4 (4), 201-217.

Seippel, O. (2006). The meanings of sport : Fun, health, beauty or community? Sport in Society, 9 (1), $51-70$.

The European Health and Fitness Report (2015). Retrieved from www.virke.no.

Zeithaml, V.A., Bitner, M.J. \& Gremler, D.D. (2006). Service marketing: Integrating customer focus across the firm (4th ed.). New York, NY: McGraw-Hill//rwin.

Zeithaml, V. \& Bitner, M. (2003) Service Marketing: Integrating Customer Focus across the Firm. New York: McGraw-Hill.

Cite this article aS: Gocłowska, S., Piątkowska, M. (2017). Service Satisfaction and Sport Consumption in The Fitness Center in Warsaw. European Journal of Service Management, 22 (2), 31-37. DOI: 10.18276/ejsm.2017.22-04. 